\title{
Improving Cross-Functional Communication About Product Architecture
}

\author{
M. J. F. Wouters ${ }^{1}$, I. C. Kerssens-van Drongelen ${ }^{2}$ \\ ${ }^{1,2}$ School of Business, Public Administration, and Technology, University of Twente, The Netherlands, \\ m.j.f.wouters@bbt.utwente.nl and i.c.kerssens-vandrongelen@bbt.utwente.nl
}

\begin{abstract}
Product architecture decisions, such as product modularity, component commonality, and design reuse, are important for balancing costs, responsiveness, quality, and other important business objectives. Firms are challenged with complex tradeoffs between competing design priorities, face the need to facilitate communication between functional silos, and to learn from past experiences. In this paper we present a qualitative approach for systematically evaluating the product architecture of an existing product or product family, linking the original architecture objectives and actual experiences. The intended contribution of our research is to present a framework that brings together a diverse set of product architecture-related decisions that are relevant from a business point of view (and not from a technical point of view) and a set of business performance elements. This framework can be used in workshop that improves cross-functional communication about the product architecture of an existing product family, and this results in practical improvement actions for future architecture design projects. Initial experiences with this approach have been obtained in pilots with Philips Domestic Appliances \& Personal Care, and Philips Consumer Electronics.
\end{abstract}

Keywords-Product architectures, new product development, inter-functional communication

\section{INTRODUCTION}

There is growing attention for product architecture decisions and the effects of these decisions on business functions such as marketing, supply chain management, production, and cost management [18]. A product architecture is a translation of functional requirements into a physical definition of building blocks: the functional decomposition of a product into subsystems, components, and parts, and the complete specification of the interfaces between these subsystems, components and parts describing how these interact within the product [21]. Product architecture decisions are typically made during what [29] called "the system-level design phase" of a product creation process.

Product architecture decisions do not only affect costs (such as development costs, product costs, service and other after-sales costs), but these also-and sometimes more importantly-provide or hamper opportunities to leverage current product technology and functionality into new products and markets [16] [28]

The product architecture concept is applied in a variety of industries described in the literature, for example, the automotive industry [13][3], the printer and copier business [11], consumer electronics [24], and power tools [17].

Previous research in the area of product architecture has particularly provided design approaches for developing and implementing product architecture policies. These approaches often focus on one specific architecture decision, such as modularity, commonality, re-use of components, and "design for X"; see, for example, [1] [3] [4] [5] [6] [7] [9] [14] [15] [16] [19] [20].

In this paper we discuss a product architecture evaluation approach that is complementary to existing methods, being different in that (1) several aspects of product architectures and their potential impact on business performance aspects are presented in a coherent framework; (2) the variables in this framework are operationalized into a set of metrics that can be used to quantify the current state of a specific product architecture; and (3) the evaluation approach is about systematically exchanging information about existing product architectures from various perspectives and experiences in the organization. Systematically here means: an approach for structuring the communication, rather than a formally defined design approach. The application of the product architecture concept requires that various disciplines such as Engineering, Design, and Marketing work together in teams and coordinate their efforts. Notions such as integration, learning, and functional cooperation are the background of the approach presented here, and as such our approach complements the existing quantitative design methods that focus on specific decisions.

This paper is based on empirical work with Philips' Center for Industrial Technology. This center supports product divisions of Philips and high-tech companies outside Philips in areas such as technological innovation, industrial technology and equipment, product innovation, and business and strategic topics. The approach was developed based on discussions with experts who could draw on their experience in product architecture development projects, which provided both content to the approach (what should be in the framework, how can it be measured) as well ideas about how the approach might be used in a real setting. The approach was tested at two sites of Philips to provide feedback on the practical usability of the framework as well as the metrics. 


\section{PRODUCT ARCHITECTURE EVALUATION APPROACH}

The product architecture evaluation approach is a structured method to discuss an existing product architecture and its impact on the business performance, to learn from it, and to give recommendations towards future product architectures. The approach consists of a questionnaire and a workshop, which should be attended by representatives from several functions in the organization that are or were somehow involved in the creation and management of the product architecture.

In the approach, the "relation matrices" framework plays an important role. The framework, which is presented in Fig. 1, is intended to clarify how product architecture decisions are linked to performance at business unit level via the intermediate concepts of product architecture capabilities, and performance at organizational level. The matrices are not exhaustive, but bring together relevant issues from different business functions. The variables in the matrices are described in the next sections, and specific metrics are formulated (not included in this paper due to space restrictions) for measuring these.

\section{A. Product architecture decisions}

The notion of a product architecture as the translation of functional requirements into a physical definition of building blocks is something that applies to many different kinds of industries. The product architecture decisions are choices with respect to re-use, commonality, modularity, integrality and "anticipation means". These decisions affect the physical composition of the product.

$R e$-use is the decision to re-use part of the product architecture in a subsequent product generation [23]. Reuse works backward and forward: first, re-use takes place when attributes from a previous generation are brought over to the present generation of the product architecture. Secondly, re-use can take place when planning to use particular attributes again in future generations of the product architecture. In essence, re-use contributes to the standardization of the product architecture over several generations. Three levels of re-use can be distinguished: 1) re-use on solution level, 2) re-use on design level (ready for copy-paste), and 3) re-use on physical level (for example building blocks and interfaces) [2]. Application of re-use may result in improved efficiency, lower risks and faster time-to-market. Re-use on product level will enable re-use in production equipment, resulting in further efficiency and economy of scale benefits.

For example, in a product family of Philips electric toothbrushes (see also [22]), the bristle unit and the interface between bristle unit and the power unit were reused: it is taken over from a previous generation to maintain compatibility with replacement brushes. It was judged that the interface would not restrict foreseen innovations in these units during the lifecycle of these products. The bristle unit itself was re-used, since it still met the functional and performance requirements. No building blocks or interfaces are defined for necessarily being re-used in a future architecture, nor are any excluded for use in a future product generation.

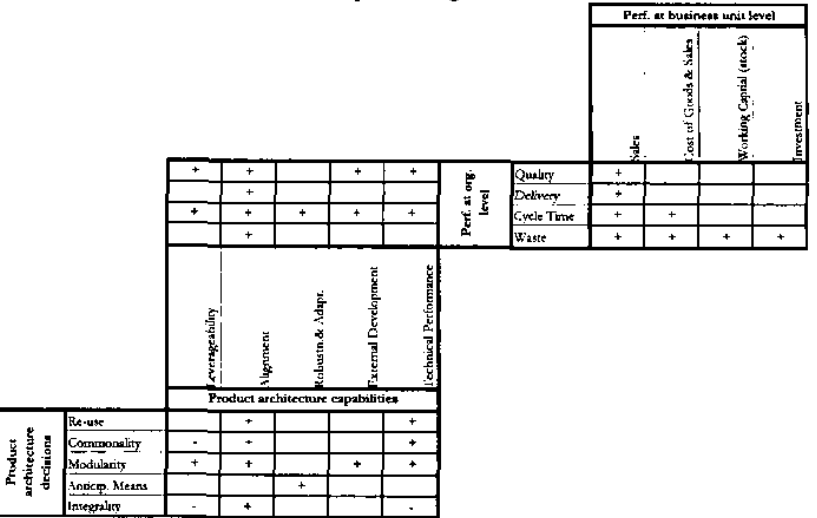

Fig. 1 Matrices to describe possible relationships between product architecture decisions and product performance

Commonality refers to the decision to use attributes across product variants in a product range [29], for example covering one product family. Commonality contributes to the standardization of product architectures. Commonality in building blocks for a specific product range also requires interface definition or standardization for this range. Commonality in product variants can be realized at several levels of abstraction, which are: specification, physical principle, solution, technology, building blocks, parts and modules. Commonality on product level (just as re-use) enables commonality in production equipment. In the electric toothbrush mentioned above, the charger unit was common for all product variants in the product range.

A key distinction can be made between integral and modular product architectures [28]. An integral architecture means that many different functions are fulfilled by one physical unit of the product, while a modular architecture means that one physical unit fulfils one (or a limited set of complete) function(s). The ideal is that it is possible to exchange one module for another with different characteristics (cost, quality, or functionality) without having to make any changes in other modules or parts of the product. This requires design characteristics such as standardized interfaces between modules and modules that are separately testable [27] configurable, and can be developed independently by suppliers (rather than individual parts) [18]. Modularized products facilitate product differentiation to meet the market requirements now and in the future [28].

In the electric toothbrush, the housing unit and the printed circuit board are modular building blocks and, hence, require standardized interfaces. Easy substitutability to offer product differentiation is possible by changing the printed circuit board or the housing unit independently from each other. 
Integrality is more or less the opposite of modularity: the decision to combine multiple functions on one building block, consciously accepting the high internal physical and functional coupling resulting from this integration. In the toothbrush example, the power unit is an integral building block. Here, the battery, motion converter, motor, switch, and charging functions are mapped on one building block.

Anticipation means are consciously built-in solutions in a product architecture to anticipate on foreseen changes and "known unknown" uncertainties in the future: uncertainty as a form of ignorance when decision-makers are aware of a factor that could affect a situation, but do not know how to assess or handle the possible impact of that factor on the situation. The anticipation can take place in the following areas: available technologies in the future, ways how components are realized in the future, shifts in the business model, changes in the industrial setting, changes in an organization's strategic outsourcing policy, changes in specific standards \& regulations, changes in external development opportunities and efficiency \& effectiveness improvements programs [20]. Anticipation to these uncertainties could be done through, for example, configurability (building blocks can be added or removed), scalability (the functionality of a common building block can be turned on or off or its parameters can be tuned) or separation (a specific function is deliberately assigned to a separate building block). The aim of these anticipation means is to keep certain options open (not to exclude them in advance) or to prevent significantly risky, costly and time-consuming modifications once adaptations are necessary in the future.

\section{B. Product-architecture capabilities}

Product-architecture capabilities describe the goals that the product architecture should realize by the right 'product architecture decisions' as discussed in the previous section. In other words, the 'product architecture capabilities' show what the product architecture is actually capable of. These capabilities are discerned into: technical performance, leveragability, alignment, adaptability \& robustness, and external development opportunities.

Technical performance is probably the most dominant and initial objective that should be realized by the product architecture. The product architecture should enable the correct technical functioning of the product variants in the first place. If this is not achieved, all other architecture objectives do not make any sense. This aspect is not the scope of this paper.

Leveragability is the ability to efficiently and effectively develop and create product variants from a set of building blocks and standardized interfaces that are compliant with a defined reference architecture [21] [15] [25]. It needs to be stressed that leveragability deals with the planned number of product variants that might be actually developed and marketed over the lifecycle of the product architecture, some of which are initially developed, and other product variants are developed after the initial range is introduced in the market.

Alignment means that the product architecture will be defined in line with the requirements or capabilities of the production system and the supply chain (including the supply base). The product architecture that needs to be defined can take these requirements into consideration and incorporate them, which leads to substantial benefits [26]. The alignment between the product architecture and the production system covers the aspects of a common product structure, a common production flow, a common production structure, common interfaces between product and production means, the number and testability of subassemblies and the proliferation of product diversity throughout production. The elements that describe the alignment between the product architecture and the supply chain and supply base characteristics can be discerned into: number of building blocks (including variants per building block), number of product variants, match of diversity profile with the customer order de-coupling point, and the match between the building block characteristics with the supplier capabilities $[8][10][11]$.

Adaptability \& Robustness: Product architectures are defined for a specific time frame, not for just the moment. When considering the future, changes can occur and uncertainties can show up in various forms and to different extents as mentioned before. Robustness describes the desired ability to adjust the product architecture to the foreseen changes and 'known unknown' uncertainties in the future. The way these adjustments are actually realized is called adaptability. Adaptability describes the desired ability to adjust the product architecture or its building blocks (in case this purpose has been decided for) in a fast, low cost and low risk manner. These adjustments should be made without considerable modifications in the product architecture. Hereby can be thought of: adjustments that do not have an impact on the interfaces of the product architecture, and the deployment of solutions based on 'anticipation means' decisions in the product architecture to adjust the product to this foreseen change or uncertainty.

External development opportunities: Sometimes other parties have superior competencies in developing the physical realization of required product functionalities. To be able to work effectively with other parties, conscious decisions need to be made which parts of the product architecture will be further detailed in-house and which will be developed externally. The product architecture can be defined as to make it easily possible to use these external development capabilities in an efficient way [18]. External development can be discerned into 1) cooperation with other organization(s), 2) fully outsourcing to another organization, or 3 ) purchasing and applying of available standard building blocks.

Within the 'Sunshine' project, a standard motor is used in the power unit and next to this the development of the complete charger is outsourced. 


\section{Performance at organizational level}

The 'product architecture capabilities' measurably affect the performance of departments such as Marketing, Production, Supply Chain Management and Development. Reference [12] explicitly makes a distinction between external and internal performance. From an external point of view, the customers determine what is important to measure: quality and delivery. From an internal perspective, the own organization determines what is important to measure, being cycle time and waste.

Quality can be described in many ways and there is even no straightforward all-embracing proper definition of quality. Quality deals with: features, performance, durability, reliability, aesthetics, perceived quality, and the extent to which the product satisfies customer requirements.

Delivery is defined as the quantity of the product or service delivered on time to the customer, as requested by the customer. The underlying elements of "delivery" are discerned into: supply chain reliability, volume flexibility and mix flexibility. Reliability in the supply chain addresses the extent to which customer orders are realized.

Cycle time represents all time-related activities of an organization's departments, both horizontal and vertical time. The horizontal time represents the time span between two points, for example: time to market, customer order lead-time, supply cycle-time, throughput cycle-time or time to quality. The vertical time represents the required efforts to get things realized. This can be measured by, for example, the development effort [17] or the (in)direct labor content.

Waste is described as all non-value adding activities and resources that are incurred in eventually meeting the customers' requirements.

\section{Performance at business unit level}

The ultimate goal of developing, manufacturing and selling products is, of course, to realize a certain profit. The performance at organizational level can be discerned into: sales, cost of goods sold, working capital and investment. Also here, a distinction is made in performance from both external and internal perspective. "Sales" represents the external perspective and "cost of goods sold", "working capital" and "investment" represent the internal perspective. These four ingredients are used within Philips' accounting method to calculate the overall profitability, and it is derived from the classic Dupont scheme.

\section{APPLYING THE PRODUCT ARCHITECTURE EVALUATION APPROACH}

The relation matrices framework described above forms the basis of our product architecture evaluation approach. The primary objective of this evaluation approach is to facilitate communication and exchange of knowledge among the relevant business functions. It consists of a questionnaire and a workshop.

The questionnaire has to be completed by the workshop participants in advance of the workshop. It is used to (1) stimulate workshop participants to think in advance about the product architecture and its impact on the business and (2) gather information that is used during the workshop to start the discussion.

The purpose of the workshop is to provide a structured learning experience regarding product architecture implications, and to generate recommendations about future product architecture decisions for similar products. The discussion is stimulated and structured through the questionnaire results and the relation matrices. In the workshop, it is discussed which relationships in the interaction matrices are most prominent, why this is so, and how this is related to decisions made during product development. The 'plus' and 'minus' symbols in Fig. 1 are suggestions for such relationships, based on the literature. However, as discussed in our introduction, to our knowledge the relationships between product architecture decisions and business performances have not yet been studied in such an integrated way. Hence the set of relationships show in Fig. 1 is probably not complete. Furthermore, not all of the presented relationships have been empirically validated and some may only apply under specific conditions. Thus, the plusses and minuses should only be used as a starting point for discussion, and the workshop participants should discuss the specific relationships in their own case, focusing on:

- intended relationships that turned out to be successful, which can lead to some good practices to be maintained for future projects;

- intended links that turned out to be unsuccessful, which can lead to recommendations what to do differently next time;

- unintended or unforeseen links, and in case of missed opportunities, recommendations can be made how to consciously deal with these links;

- relationships between product architecture and its impact on the performance at organizational and businessunit level, which can lead to concrete ideas for better serving business goals in future projects.

The result of the workshop is a list of concrete recommendations for future product architectures of similar products.

\section{CONCLUSIONS AND FURTHER RESEARCH}

Product-architecture decisions have a significant impact on an organization's ability to implement its strategy, because these decisions impact the speed and cost by which a firm can introduce new products, and the potential quality and functionality of these products. Studies in the literature have investigated many tradeoffs involved in product architecture decisions, and models for 
such tradeoffs have been developed. Also, successful applications of deliberate product architectures are reported in the literature. In this paper, we have discussed an approach for evaluating the product architecture of a firm's current products, in order to draw lessons for new products that the firm will develop. The approach is qualitative in the sense that it is about stimulating and organizing the exchange of knowledge, data, experiences from various functional silos and management levels in the organization in a workshop setting and through a preparatory questionnaire.

The approach considers various aspects that are related to product architecture, and this is a contribution to the literature, where evaluation approaches are usually focused on more rigorous evaluations of one single product-architecture related topic. The framework is summarized in Fig. 1. The approach was in close cooperation with Philips' Center for Industrial Technology. Future research could be aimed at testing the approach in pilot projects and real-life settings in industry.

\section{REFERENCES}

[1] C.Y. Baldwin and K. B. Clark, Design rules: The power of modularity. The MIT Press, Cambridge, 2000.

[2] M. Corso, M. Muffatto, and R. Verganti, "Reusability and multi-product development policies: A comparison of approaches in the automotive, motorcycle and earthmoving machinery industries," Robotics and Computer-Integrated Manufacturing, vol. 15, pp. 155-165, 1999.

[3] J. B. Dahmus, J. P. Gonzalez-Zugasti, and K. N. Otto, “Modular product architecture," Design Studies, vol. 22, pp. 409-424, 2001

[4] K. Fujita, "Product variety optimization under modular architecture," Computer-Aided Design, vol. 34, pp. 953-965, 2002.

[5] J. K. Gershenson, G. J. Prasad, and Y. Zhang, "Product modularity: measures and design methods," Journal of Engineering Design, vol. 15, no. 1, pp. 33-51, 2004.

[6] J. P. Gonzalez-Zugasti, K. Otto, and J. D. Baker, "A method for architecting product platforms," Research in Engineering Design, vol. 12 , pp. $61-72,2000$.

[7] J. Jiao and M. Tseng, "Understanding product family for mass customization by developing commonality indices," Journal of Engineering Design, vol. 11, no. 3, pp. 225-243, 2000.

[8] V. Krishnan and K. T. Ulrich, "Product development decisions: A revicw of the literature," Management Science, vol. 47 , no. 1 , pp. 1-21, 2001

[9] T. C. Kuo, S. H. Huang, and H. C. Zhang, "Design for manufacture and design for ' $\mathrm{X}$ ': concepts, applications, and perspectives," Computers and Industrial Engineering, vol. 41, pp. 241-260, 2001.

[10] A. Kusiak, "Integrated product and process design: A modularity perspective," Journal of Engineering Design, vol. 13 , no. 3, pp. 223-231, 2002
[11] H. L. Lee, "Effective inventory \& service management through product and process redesign," Operations Research, vol. 44, no, 1, pp. 151-159, 1996

[12] R. Lynch and K. F. Cross, Measure Up! Yardsticks for continuous improvement. Blackwell Publishers, Cambridge, 1991.

[13] J. P. MacDuffie, K. Sethuraman, and M. L. Fisher, "Product variety and manufacturing performance: Evidence from the international automotive assembly plant study," Management Science, vol. 42, pp. 350-369, 1996.

[14] R. Marshall and P. G. Leaney, "Holinic product design: A process for modular product realization," Journal of Engineering Design, vol. 13, no. 4, pp. 293-303, 2002.

[15] M. V. Martin, Design for variety: A methodology for developing product platform architectures. Stanford University, Department of Mechanical Engineering, dissertation, 1999.

[16] M. H. Meyer and D. Dalal, "Managing platform architectures and manufacturing processes for non-assembled products," Journal of Product Innovation Management, vol. 19, no. 4, pp. 277-293, 2002.

[17] M. H. Meyer and A. P. Lehnerd, The power of product platform: Building value and cost leadership. The Free Press, New York, 1997

[18] J. H. Mikkola, "Modularity, component outsourcing, and inter-firm learning," $R \& D$ Management, vol. 33 , no. 4 , pp. 439-454, 2003.

[19] R. U. Nayak, W. Chen, and T. W. Simpson, "A variationbased method for product family design," Engineering Optimization, vol. 34, no. 1, pp. 65-81, 2002.

[20] S. Robertson and K. T. Ulrich, "Planning for product platforms," Sloan Management Review, vol. 39, no. 4, pp. 19-31, Summer 1998.

[21] R. Sanchez, "Strategic product creation: Managing new interactions of technology, markets and organisations," European Management Journal, vol. 14, no. 2, pp. 121-138, 1996.

[22] R. Sanchez, "Creating modular platforms for strategic flexibility," Design Management Review, vol. 15, no. 1, pp. 58-68, Winter 2004.

[23] S. W. Sanderson, "Cosi models for evaluating virtual design strategies in multi-cycle product families," Journal of Engineering and Technology Management, vol. 8, pp. 339358, 1991.

[24] S. Sanderson and V. Uzumeri, Managing product families. Irwin, Chicago, 1997

[25] A. Sudjinato and K. Otto, "Modularization to support multiple brand platforms," in Proceedings of ASME Design Engineering Technical Conference, 2001.

[26] M. V. Tatikonda, "An empirical study of platform and derivative product development projects," Journal of Product Innovation Management, vol. 16, pp. 3-26, 1999.

[27] Y. T. Tsai and K. S. Wang, "A study of modularity operation of systems based on maintenance consideration," Journal of Engineering Design, vol. 14, no. 1, pp. 41-56, 2003.

[28] K.T. Ulrich, "The role of product architecture in the manufacturing firm," Research Policy, vol. 24, pp. 419-440, 1995.

[29] K.T. Ulrich and S. D. Eppinger, Product design and development. McGraw-Hill, New York, 2000. 